NASA/TM-2014-218123

\title{
Noise From Aft Deck Exhaust Nozzles- Differences in Experimental Embodiments
}

James E. Bridges

Glenn Research Center, Cleveland, Ohio 


\section{NASA STI Program . . . in Profile}

Since its founding, NASA has been dedicated to the advancement of aeronautics and space science. The NASA Scientific and Technical Information (STI) program plays a key part in helping NASA maintain this important role.

The NASA STI Program operates under the auspices of the Agency Chief Information Officer. It collects, organizes, provides for archiving, and disseminates NASA's STI. The NASA STI program provides access to the NASA Aeronautics and Space Database and its public interface, the NASA Technical Reports Server, thus providing one of the largest collections of aeronautical and space science STI in the world. Results are published in both non-NASA channels and by NASA in the NASA STI Report Series, which includes the following report types:

- TECHNICAL PUBLICATION. Reports of completed research or a major significant phase of research that present the results of NASA programs and include extensive data or theoretical analysis. Includes compilations of significant scientific and technical data and information deemed to be of continuing reference value. NASA counterpart of peer-reviewed formal professional papers but has less stringent limitations on manuscript length and extent of graphic presentations.

- TECHNICAL MEMORANDUM. Scientific and technical findings that are preliminary or of specialized interest, e.g., quick release reports, working papers, and bibliographies that contain minimal annotation. Does not contain extensive analysis.

- CONTRACTOR REPORT. Scientific and technical findings by NASA-sponsored contractors and grantees.
- CONFERENCE PUBLICATION. Collected papers from scientific and technical conferences, symposia, seminars, or other meetings sponsored or cosponsored by NASA.

- SPECIAL PUBLICATION. Scientific, technical, or historical information from NASA programs, projects, and missions, often concerned with subjects having substantial public interest.

- TECHNICAL TRANSLATION. Englishlanguage translations of foreign scientific and technical material pertinent to NASA's mission.

Specialized services also include creating custom thesauri, building customized databases, organizing and publishing research results.

For more information about the NASA STI program, see the following:

- Access the NASA STI program home page at http://www.sti.nasa.gov

- E-mail your question to help@sti.nasa.gov

- Fax your question to the NASA STI Information Desk at 443-757-5803

- Phone the NASA STI Information Desk at 443-757-5802

- Write to: STI Information Desk NASA Center for AeroSpace Information 7115 Standard Drive Hanover, MD 21076-1320 
NASA/TM-2014-218123

\section{Noise From Aft Deck Exhaust Nozzles- Differences in Experimental Embodiments}

James E. Bridges

Glenn Research Center, Cleveland, Ohio

Prepared for the

SciTech 2014

sponsored by the American Institute of Aeronautics and Astronautics

National Harbor, Maryland, January 13-17, 2014

National Aeronautics and

Space Administration

Glenn Research Center

Cleveland, Ohio 44135 


\section{Acknowledgments}

This research was carried out with support of the High Speed Project under NASA's Fundamental Aeronautics Program. Discussions with Gary Podboy, Cliff Brown, and Khairul Zaman were very valuable in the preparation of this paper.

This work was sponsored by the Fundamental Aeronautics Program at the NASA Glenn Research Center.

Level of Review: This material has been technically reviewed by technical management.

Available from

NASA Center for Aerospace Information 7115 Standard Drive

Hanover, MD 21076-1320
National Technical Information Service 5301 Shawnee Road Alexandria, VA 22312 


\title{
Noise From Aft Deck Exhaust Nozzles-Differences in Experimental Embodiments
}

\author{
James E. Bridges \\ National Aeronautics and Space Administration \\ Glenn Research Center \\ Cleveland, Ohio 44135
}

\begin{abstract}
Two embodiments of a rectangular nozzle on an aft deck are compared. In one embodiment the lower lip of the nozzle was extended with the sidewalls becoming triangles. In a second embodiment a rectangular nozzle was fitted with a surface that fit flush to the lower lip and extended outward from the sides of the nozzle, approximating a semi-infinite plane. For the purpose of scale-model testing, making the aft deck an integral part of the nozzle is possible for relatively short deck lengths, but a separate plate model is more flexible, accounts for the expanse of deck to the sides of the nozzle, and allows the nozzle to stand off from the deck. Both embodiments were tested and acoustic far-field results were compared. In both embodiments the extended deck introduces a new noise source, but the amplitude of the new source was dependent upon the span (cross-stream dimension) of the aft deck. The noise increased with deck length (streamwise dimension), and in the case of the beveled nozzle it increased with increasing aspect ratio. In previous studies of slot jets in wings it was noted that the increased noise from the extended aft deck appears as a dipole at the aft deck trailing edge, an acoustic source type with different dependence on velocity than jet mixing noise. The extraneous noise produced by the aft deck in the present studies also shows this behavior both in directivity and in velocity scaling.
\end{abstract}

\section{Nomenclature}

$D_{e} \quad$ diameter, equivalent area

$H \quad$ short dimension of rectangular nozzle exit

$L \quad$ length of bevel beyond exit of baseline nozzle

$h \quad$ standoff height of plate surface from nozzle lip

$x_{T E} \quad$ distance from nozzle exit to trailing edge of plate surface

$\mathrm{Ma} \quad$ acoustic Mach number, $U_{j} / a_{\infty}$

$U_{j} \quad$ ideally expanded jet velocity

$a_{\infty} \quad$ speed of sound, ambient

\section{Introduction}

Supersonic civilian aircraft will have to be considerably different than conventional aircraft because their shaping is critical to minimizing the boom heard on the ground. One part of this shaping may be to artfully embed the propulsion in the airframe, minimizing the sudden variations in aircraft cross-section or perhaps hiding pressure sources from non-ideally expanded plumes from reaching observers below the vehicle. Such tight integration of the propulsion offers potential noise reduction from the propulsion, but may also yield additional noise challenges. Low-speed applications of slot nozzles include blended-wing architectures with distributed propulsion, and high-lift concepts for short take-off operation. 
Embedded propulsion concepts often entail two geometric features beyond a simple round nozzle: high aspect ratio cross-section and an extended aft deck. The propulsion exhaust can be on the upper or lower side of the aircraft. The aspect ratio can vary significantly, but practical concerns regarding propulsion performance typically drive designs toward smaller aspect ratios unless there are other overriding objectives that require high aspect ratio. For instance, in the early years of jet propulsion various schemes of augmenting lift by routing exhaust air through slots over airfoils were considered (Refs. 1 and 2 ). In these studies, aspect ratios up to 100 or more were considered. These exhaust schemes were typically much louder than equivalent isolated round jets, giving concern for current concepts with embedded propulsion.

Research into the causes for the enhanced noise of a jet over a lifting surface looked at changes in the turbulent mixing noise and the addition of a new source from the scattering of turbulent energy as sound. In early studies (Refs. 3 and 4) of the turbulence of a slot jet over a surface it was noted that the turbulence in the shear layer beginning at the trailing edge of the extended surface was amplified relative to a simple jet shear layer, the degree and scale of the turbulence depending upon the length of the surface downstream of the nozzle exit. This mixing noise source would presumably be addressed by acoustic analogy theory, perhaps with a custom Green's function. Having noise be generated by scattering at the trailing edge would require a more specialized analysis, such as was first pursued in 1978 (Ref. 5) and is being revived. Wellestablished work on trailing edge noise of airfoils (Ref. 6) may also be a fruitful approach to this problem. Experimental and modeling work is also underway to isolate the trailing edge dipole and empirically model this source in the specific case of a round jet over an extended surface (Ref. 7).

If there are important gains to be made in aircraft design by having embedded propulsion, the lack of validated predictive tools for the problem of turbulent plumes exhausting over surfaces is a significant issue. Most acoustic analogies for jet noise, using Reynolds-Averaged Navier-Stokes computations to provide the flow quantities required, treat only free-space jets, assuming no solid surfaces are nearby the jet plume. Recent research at NASA is developing a comprehensive database for the impact of solid surfaces on jet noise. Strong changes that develop in the flow and noise as the surface comes very close to the jet plume are being documented along with the acoustic impact of the surface. Affiliated theoretical development using a rapid distortion theory has attempted to capture this change in terms of a dipole source located at the trailing edge of the surface. This theory is very sensitive to the mean profile and turbulence near the surface and in some ways is not directly applicable to the problem where the jet flow is directly on the surface. Even large eddy simulations (LES) have only recently been applied to this problem, and require validation and guidance as necessary simplifications (particularly regarding the need to resolve the boundary layer on the surface) that must come from experiments. And finally, systems engineers working on vehicle concepts for supersonic flight need simplified, empirical models to make trades among the different performance objectives of the aircraft. For example, the semi-empirical modeling developed by Munro (Ref. 8) allows prediction of noise from high aspect ratio jets. In current studies by the NASA High Speed Project aircraft configurations are being studied with low to moderate aspect ratios and with the nozzle exhausting on or near an aft deck, requiring a bit different design space be explored. To this purpose a research program was conceived, intended to systematically extend knowledge of jet noise from single round jets and round jets with parallel surface to rectangular jets with and without nearby surfaces.

In 2011 an extensive set of acoustic data was acquired on single-flow convergent rectangular nozzles of aspect ratios $2: 1,4: 1$, and 8:1. In addition to variation in aspect ratio, several versions of these nozzles were tested that had an extension of one wide side of the nozzle, characterized as making a 'beveled' nozzle. These nozzles are also representative of exhaust systems with a slot nozzle exiting over an aft deck of the aircraft. One outcome of the Extensible Rectangular Nozzle (ERN11) test program was an empirical model for how the spectral directivity was affected by the geometry of the nozzle relative to a convergent axisymmetric nozzle (Ref. 9). This model, with variables of aspect ratio and aft deck length, consisted of a bilinear polynomial in scaled versions of these variables, and was created to be a model in the new empirical module in NASA's aircraft noise prediction code ANOPP2. This prediction module 
was limited in the range of aspect ratios and deck lengths that it spanned, and by the initial assumption that the geometric effects on the noise would be independent of jet flow condition.

By 2013 work on the noise impact of round nozzles near surfaces had progressed (Ref. 10) such that more extensive questions were being asked regarding how having a surface extend far beyond the flowscrubbing part of the nozzle or how having the nozzle standoff from the surface by some amount would change the sound. This became part of the TwinRect/AftDeck test carried out from January to May 2013, specifically, the first part of the test, which was done on the Small Hot Jet Acoustic Rig (SHJAR) in NASA's Aero-Acoustic Propulsion Lab for single nozzles near surfaces. During this testing the basic rectangular nozzles were again tested but a moving plate that extended upstream and to the sides to approximate a semi-infinite surface replaced the 'bevel' or extended lip of the nozzle. The plate could be moved from the lip line outward with a linear actuator, and interchangeable surface extension pieces allowed different lengths of plate beyond the nozzle exit. The length of the plate beyond the nozzle exit was denoted $x_{T E}$ for trailing edge length, and the standoff from the nozzle lip was designated $h$. Two of the new moving plate configurations replicated the two $x_{T E}$ that had been tested as integral to the rectangular nozzles in ERN11. This configuration could only be acoustically measured in the $0^{\circ}$ and $180^{\circ}$ azimuthal planes (called 'reflected' and 'shielded', respectively in previous jet-surface interaction testing). Geometrically, the range of aft deck lengths covered by the original model was relatively small, extending only up to $x_{T E} / D_{e}=1.25$. In the current work the model has been extended in $x_{T E} / D_{e}$ using the separate plate hardware, up to aft deck lengths of $x_{T E} / D_{e}=5.6$, for a more complete parametric range of aft deck extensions.

This paper will describe the results of the testing of rectangular nozzles with aft deck surfaces that are coplanar with the lower lip of the nozzle. It will compare and contrast the acoustic impact of the aft deck surface as simulated by a beveled, integral, lower lip, and by a semi-infinite surface.

\section{Experimental Facility}

All data in this report were acquired on the Small Hot Jet Acoustic Rig (SHJAR) in NASA's AeroAcoustic Propulsion Lab at NASA Glenn Research Center. Details of the SHJAR and of the anechoic Aero-Acoustic Propulsion Lab can be found in a report (Ref. 11) detailing the basic round jet noise performance of the rig. Of significance here: acoustic data were acquired on a 150 in. $(3.8 \mathrm{~m})$ arc using twenty-four $1 / 4$ in. Bruel \& Kjaer condenser microphones at a $5^{\circ}$ spacing from $50^{\circ}$ to $165^{\circ}$ relative to the forward flight direction. All data presented have had atmospheric attenuation added back to the spectrum and have been transformed to an arc with radius of 100 equivalent jet diameters assuming spherical spreading from the jet exit. The flow conditions were controlled to maintain jet velocity relative to ambient speed of sound (acoustic Mach number Ma) to within 0.5 percent of stated values.

\section{Model Hardware}

The rectangular nozzles were designed to deliver a flat velocity profile at the rectangular nozzle exit plane, and the resultant design was documented extensively (Ref. 12). Then one wide side lip was extended with the narrow side making a triangle that connected the short and long lips. These were referred to as beveled rectangular nozzles. Although it was envisioned that many nozzles would follow with the same basic contraction and different trailing edge feature (hence the name Extensible Rectangular Nozzle system), the cost of integral fabrication and the need to create a very long lip, or aft deck as it later became known, caused the adoption of a separate plate to be added to the basic rectangular nozzles. All rectangular nozzles had the same exit area, producing the same area-equivalent diameter $D_{e}=2.137$ in. 


\section{Beveled Rectangular Nozzle}

The original ERN family included nozzles of aspect ratio $2: 1,4: 1$, and $8: 1$. For each of these aspect ratios, three nozzles were fabricated: one basic nozzle with no extension, and two beveled variants with a bevel length of 1.3 and 2.7 in., denoted B1 and B2 in the nozzle naming convention. For the 2:1 and 4:1 aspect ratios a ' $\mathrm{K} 1$ ' variant was created that duplicated the B1 design but with the triangular sidewalls removed. The $\mathrm{K} 1$ variant is a critical connection between the integral bevel nozzles and the rectangular nozzles with separate aft deck. See Table 1 for naming convention and critical dimensions of the beveled nozzles. If the dimensions of the rectangular nozzles are given by their major and minor axes, the bevel lengths are that of the minor and major axes of the 2:1 nozzle, and hence twice and four times, respectively the minor axis height of the 8:1 nozzle. The 8:1 aspect ratio family is shown in Figure 1.

The nomenclature describing the beveled rectangular jet nozzles and observer angles is given in Figure 2. The bevel is created by extending one lip a distance $L$ downstream of the baseline exit. The minor axis dimension is denoted $H$. Polar angles are measured from the upstream jet axis and the azimuthal or roll angle is measured from the minor axis on the short side of the bevel.

TABLE 1.-NOZZLE CONFIGURATIONS, RECTANGULAR NOZZLES WITH EXTENSIONS

\begin{tabular}{|c|c|c|c|c|}
\hline Nozzle name & Aspect ratio & $\begin{array}{c}\text { Bevel length } L, \\
\text { inches }\end{array}$ & $L / D_{e}$ & Sidewall? \\
\hline A2Z0 & $2: 1$ & None & N/A & N/A \\
\hline A2B1 & $2: 1$ & 1.3 & 0.63 & Yes \\
\hline A2K1 & $2: 1$ & 1.3 & 0.63 & No \\
\hline A2B2 & $2: 1$ & 2.7 & 1.25 & Yes \\
\hline A4Z0 & $4: 1$ & None & N/A & N/A \\
\hline A4B1 & $4: 1$ & 1.3 & 0.63 & Yes \\
\hline A4K1 & $4: 1$ & 1.3 & 0.63 & No \\
\hline A4B2 & $4: 1$ & 2.7 & 1.25 & Yes \\
\hline A8Z0 & $8: 1$ & None & N/A & N/A \\
\hline A8B1 & $8: 1$ & 1.3 & 0.63 & Yes \\
\hline A8B2 & $8: 1$ & 2.7 & 1.25 & Yes \\
\hline
\end{tabular}
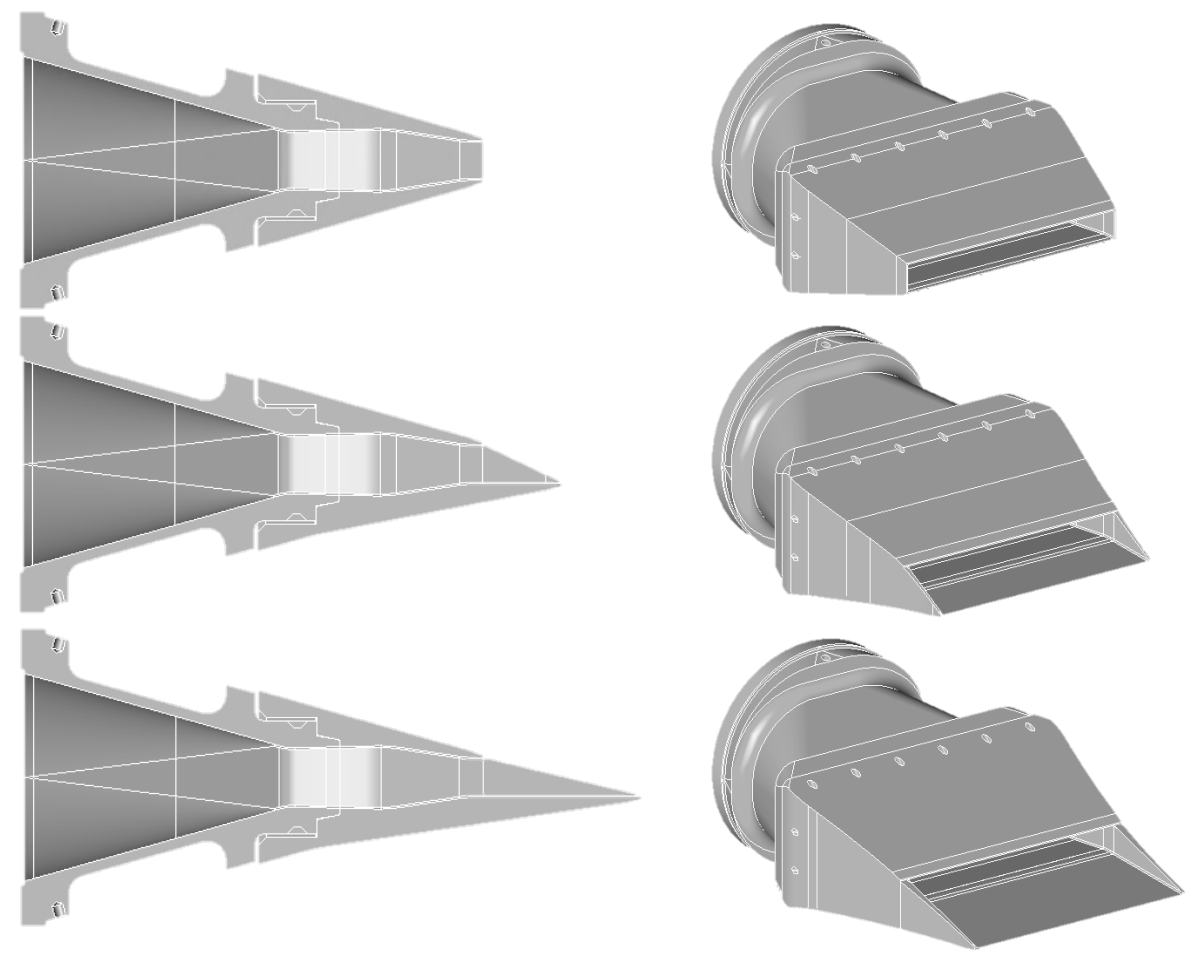

Figure 1.-Sample beveled rectangular nozzles from ERN family. From the top: A8Z0, A8B1, and A8B2. 


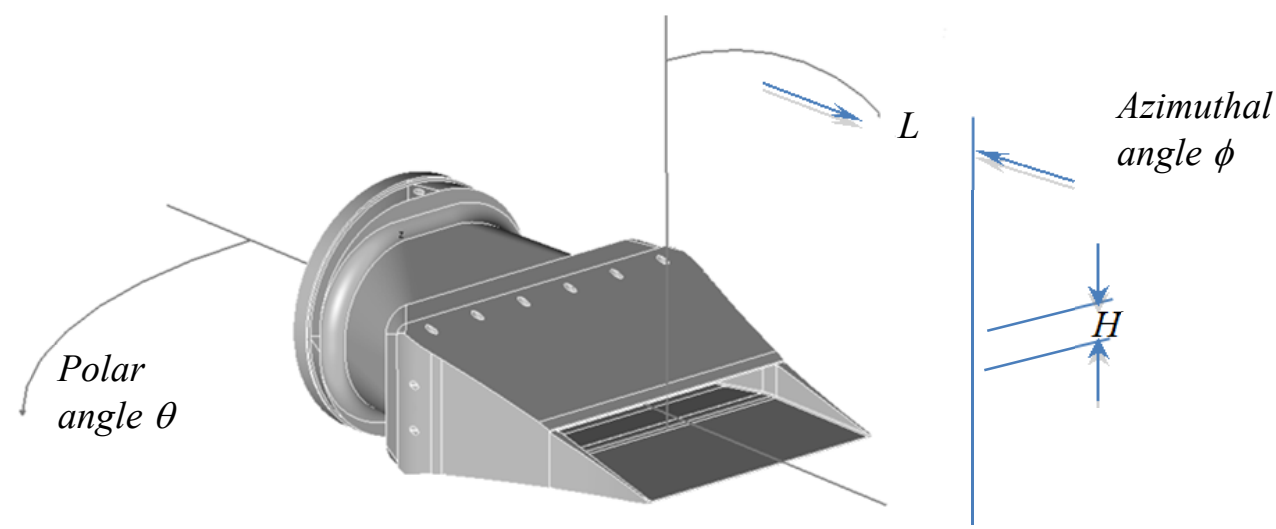

Figure 2.-Nomenclature for beveled rectangular nozzles.
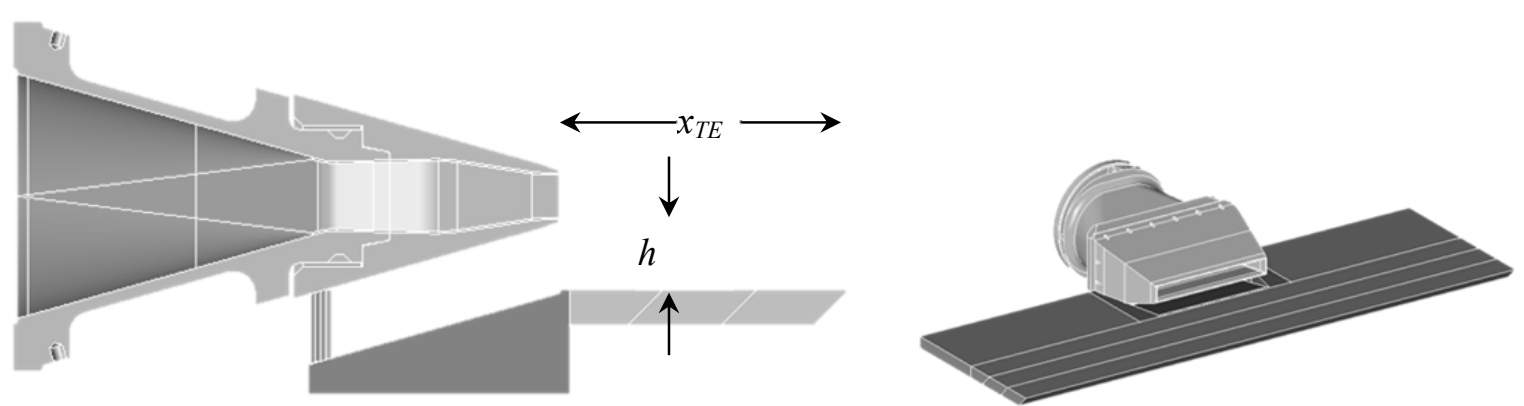

Figure 3.-Nomenclature definition for basic rectangular nozzle with surface. A8Z0 with $h=1$ in. $\left(h / D_{e}=0.45\right)$, $x_{T E}=4$ in. $\left(x_{T E} / D_{e}=1.88\right)$ shown.

\section{Rectangular Nozzle With Aft Deck Surface}

To more economically explore the effect of bevel length, or aft deck length as it became known, and to explore the effect of offsetting the nozzle flow from the deck, a new architecture of model was created. Here the basic rectangular nozzles had plates fitted to them such that when the plate surface was even with the inner lip of the wide side of the nozzle, the surface and nozzle were effectively one piece. Figure 3 shows the general layout of this model system, including definitions of the plate length $x_{T E}$ and standoff $h$. Five aft deck lengths $x_{T E}$ were tested: 1.3, 2.7, 4, 8, and 12 in. long as shown in Figure 4. Table 2 presents the nomenclature and relevant dimensions of all surface plate configurations tested. Note that the first two plate lengths $x_{T E}$ are the same as the lengths of the bevels $L$ on the integral nozzles and that for data in this paper the plate will always be congruent with the nozzle lip, e.g., $h=0$.

It may seem presumptuous to expect that the integral beveled nozzle and the nozzle with separate aft deck would be similar acoustically. After all, the integral bevel features triangular sidewalls while the separate deck has a significant (ideally infinite) span beyond the sides of the nozzle. The separate plate has a different trailing edge geometry, having a $45^{\circ}$ chisel to the $1 / 2$ in. plate rather than a 0.030 in. thick trailing edge on a very thin surface. However, along with the beveled nozzles originally fabricated, a version without the triangular sidewalls was manufactured and tested. Figure 5 compares the beveled nozzle, with and without sidewalls, with the rectangular nozzle with separate plate. Initial tests found the triangular sidewall to have little effect on the beveled nozzles' acoustic properties (shown below). Hence, there was reason to believe that the two model systems would perform in a similar manner acoustically, e.g., that $L$ and $x_{T E}$ could be used interchangeably. 
TABLE 2.-NOZZLE CONFIGURATIONS, BASE NOZZLE WITH PLATE SURFACE

\begin{tabular}{|c|c|c|c|}
\hline Nozzle name & Aspect ratio & $\begin{array}{c}\text { Plate length } x T E, \\
\text { inches }\end{array}$ & $x T E / D e$ \\
\hline A2X13 & $2: 1$ & 1.34 & 0.63 \\
\hline A2X27 & $2: 1$ & 2.68 & 1.25 \\
\hline A2X40 & $2: 1$ & 4.00 & 1.88 \\
\hline A2X80 & $2: 1$ & 8.00 & 3.74 \\
\hline A2X120 & $2: 1$ & 12.00 & 5.61 \\
\hline A4X13 & $4: 1$ & 1.34 & 0.63 \\
\hline A4X27 & $4: 1$ & 2.68 & 1.25 \\
\hline A4X40 & $4: 1$ & 4.00 & 1.88 \\
\hline A4X80 & $4: 1$ & 8.00 & 3.74 \\
\hline A4X120 & $4: 1$ & 12.00 & 5.61 \\
\hline A8X13 & $8: 1$ & 1.34 & 0.63 \\
\hline A8X27 & $8: 1$ & 2.68 & 1.25 \\
\hline A8X40 & $8: 1$ & 4.00 & 1.88 \\
\hline A8X80 & $8: 1$ & 8.00 & 3.74 \\
\hline A8X120 & $8: 1$ & 12.00 & 5.61 \\
\hline
\end{tabular}

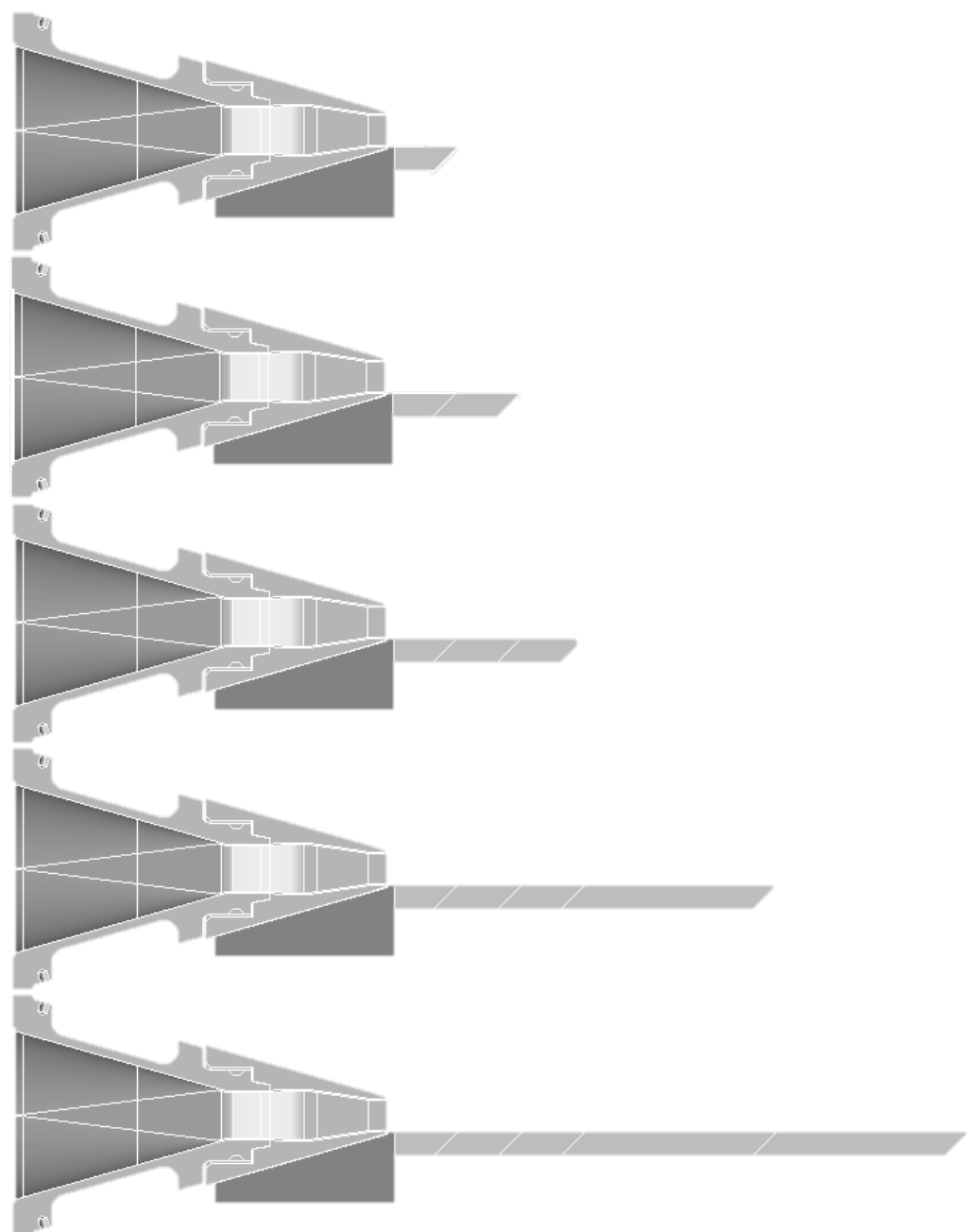

Figure 4.-A8Z0 with deck at $h=0$ and (from the top) $x_{T E}=1.3,2.7,4,8$, 12 in. 


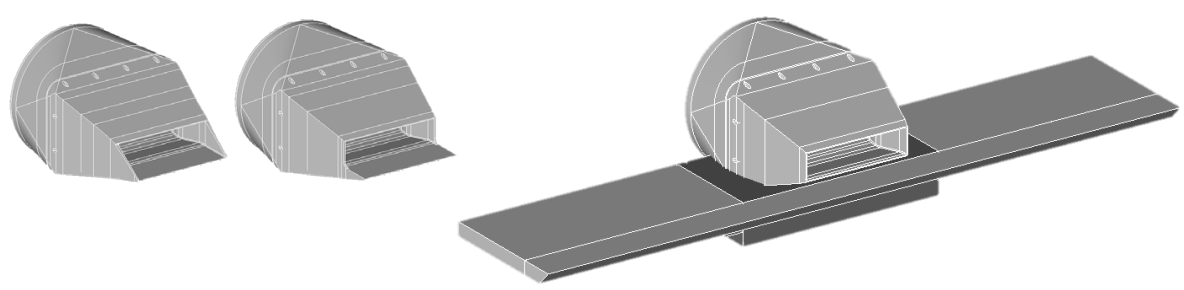

Figure 5.-Comparison of different embodiments of short aft deck on 4:1 aspect ratio nozzle: beveled nozzle with sidewalls (A4B1, left), beveled nozzle without sidewalls (A4K1, center), baseline nozzle with separate plate (A4Z0 with $x_{T E}=1.3$ in., right).

\section{Experimental Results}

Results will be presented in the following logical order: first, the effect of aspect ratio and bevel length will be presented for the beveled nozzles, showing the magnitude and character of the impact on jet spectra that the model must represent. Second, the effect of aspect ratio and aft deck length as found in experiments of baseline rectangular nozzles with a flat plate coplanar to the nozzle lip. Third, data will be presented for those cases where the two methods of approximating an aft deck overlap in variable space. In all three presentations a flow condition of acoustic Mach number $\mathrm{Ma}=0.5$ will be used to accentuate the effect of the dipole edge noise. At higher speeds the jet mixing noise, which increases with Ma approximately as (Ma) (Ref. 8), began to dominate the trailing edge noise, which increases as (Ma) (Ref. 6).

In the figures that follow, the spectra are power spectral density with frequency scaled as Strouhal number. The decibel scaling is relative to $0.4 \times 10^{-9} \mathrm{~Pa}^{2} / \mathrm{St}$. The spectra have been averaged over $1 / 12$ octave bands to allow better discrimination of the line plots.

\section{Presentation of Noise of Beveled Nozzle}

The impact of bevel length on rectangular nozzles of various aspect ratios is demonstrated in Figure 6. In each plot of the figure the power spectral density of the far-field sound at polar angle $90^{\circ}$ is shown for four different nozzles: round nozzle $(\mathrm{SMC000)}$ ), baseline rectangular nozzle $(\mathrm{A} \bullet \mathrm{Z} 0)$, and two different bevel lengths $(\mathrm{A} \bullet \mathrm{B} 1$ and $\mathrm{A} \cdot \mathrm{B} 2)$ where $\bullet$ is the aspect ratio. Spectra are shown for two azimuthal, or roll, angles, as defined in Figure 2. From the figure the 2:1 rectangular nozzle produces noise only slightly different than the round (SMC000) nozzle. The difference becomes greater as the aspect ratio increases, with the rectangular jet being quieter by as much as $3 \mathrm{~dB}$ in the case of the $8: 1$ rectangular nozzle on the major axis plane (azimuth $=0^{\circ}$ ). More striking in this plane is the increase in noise with bevel length, especially for large aspect ratios. The 8:1 nozzle with the longest bevel (A8B2) is $8 \mathrm{~dB}$ above the 8:1 nozzle without bevel. On the minor axis plane the longest bevel only adds up to $3 \mathrm{~dB}$ to the 8:1 nozzle sound.

In summary, noise is decreased in both azimuthal planes by increases in aspect ratio, but much more dramatically in the major axis plane. These reductions are quickly lost as one lip of the nozzle was extended to make an aft deck. This was the overall trend that was captured by the beveled rectangular model.

Similar to Figure 6, the plots in Figure 7 compare noise spectra at right angles to the jet axis and for two rolls angles. In these plots, however, the different spectral lines come from nozzles with the same integral lower lip built into the nozzle, but the nozzle denoted by A $\bullet \mathrm{K} 1$ did not have a sidewall, as exemplified by the middle nozzle of Figure 5. In the upper row of Figure 7, featuring the noise of the 2:1 nozzles, there is more impact of the extended lower lip when the sidewall is missing; the beveled nozzle has very little difference in noise from the basic rectangular nozzle. In the lower row, the 4:1 nozzles show more impact of the extended lower lip and the impact is independent of whether the sidewall is present or not. From these plots one might say that it is inconclusive whether the sidewall has an acoustic impact or not, depending upon the aspect ratio. For higher aspect ratios where the length of the surface relative to the minor axis dimension is greater, the sidewall did not seem to make a difference. Based on this, it was expected that longer lower lips or surfaces would have more effect, and that this effect would not depend upon the presence of sidewalls. 

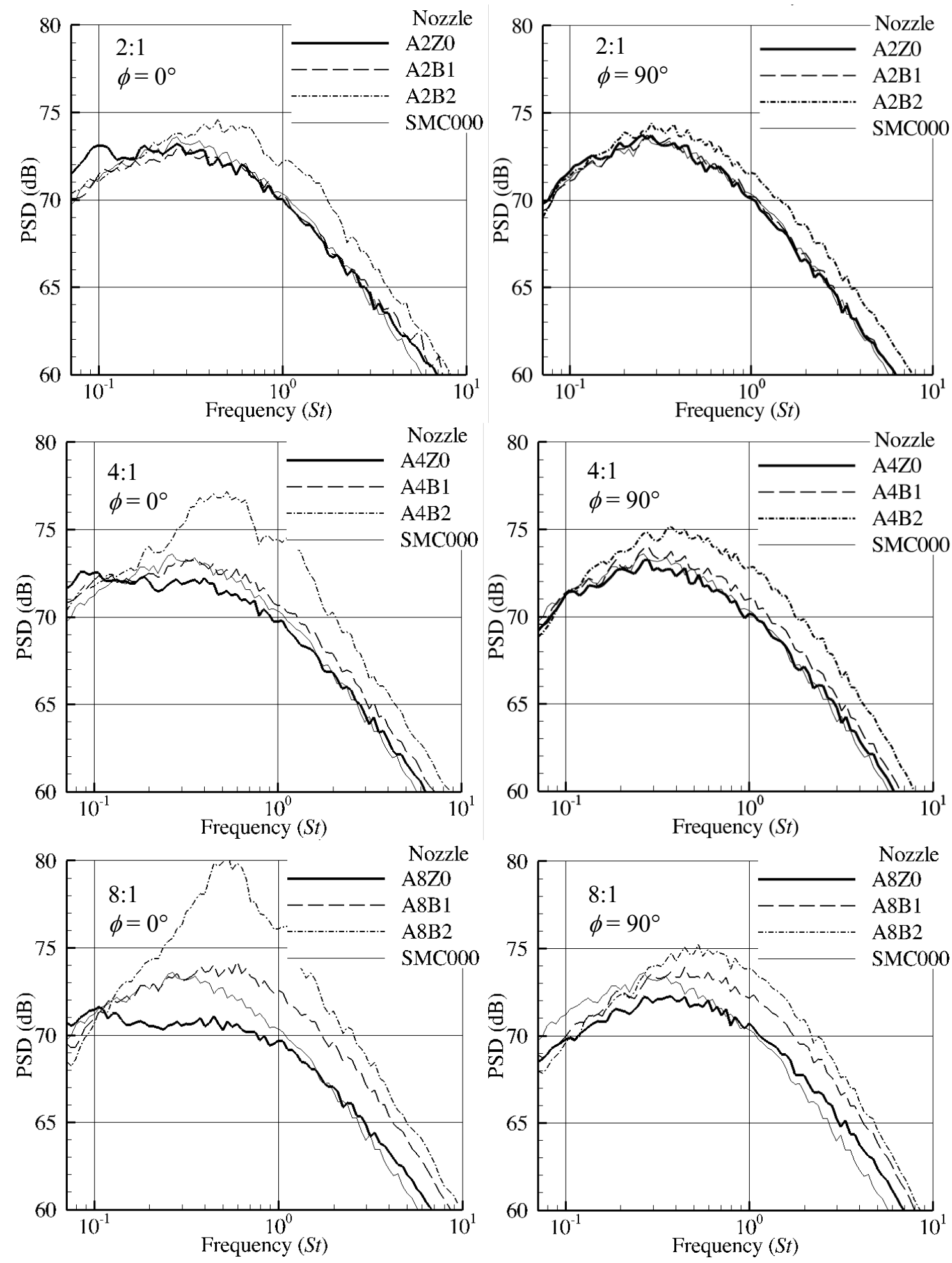

Figure 6.-Power spectral density at polar angle $90^{\circ}$ and azimuthal angles $0^{\circ}$ (left) and $90^{\circ}$ (right) for $2: 1$ (top), 4:1 (middle), and 8:1 (bottom) beveled nozzles with different bevel lengths. The round nozzle $\mathrm{SMC000}$ is included in the plots for reference. All jets were run unheated at Ma $=0.5$. 

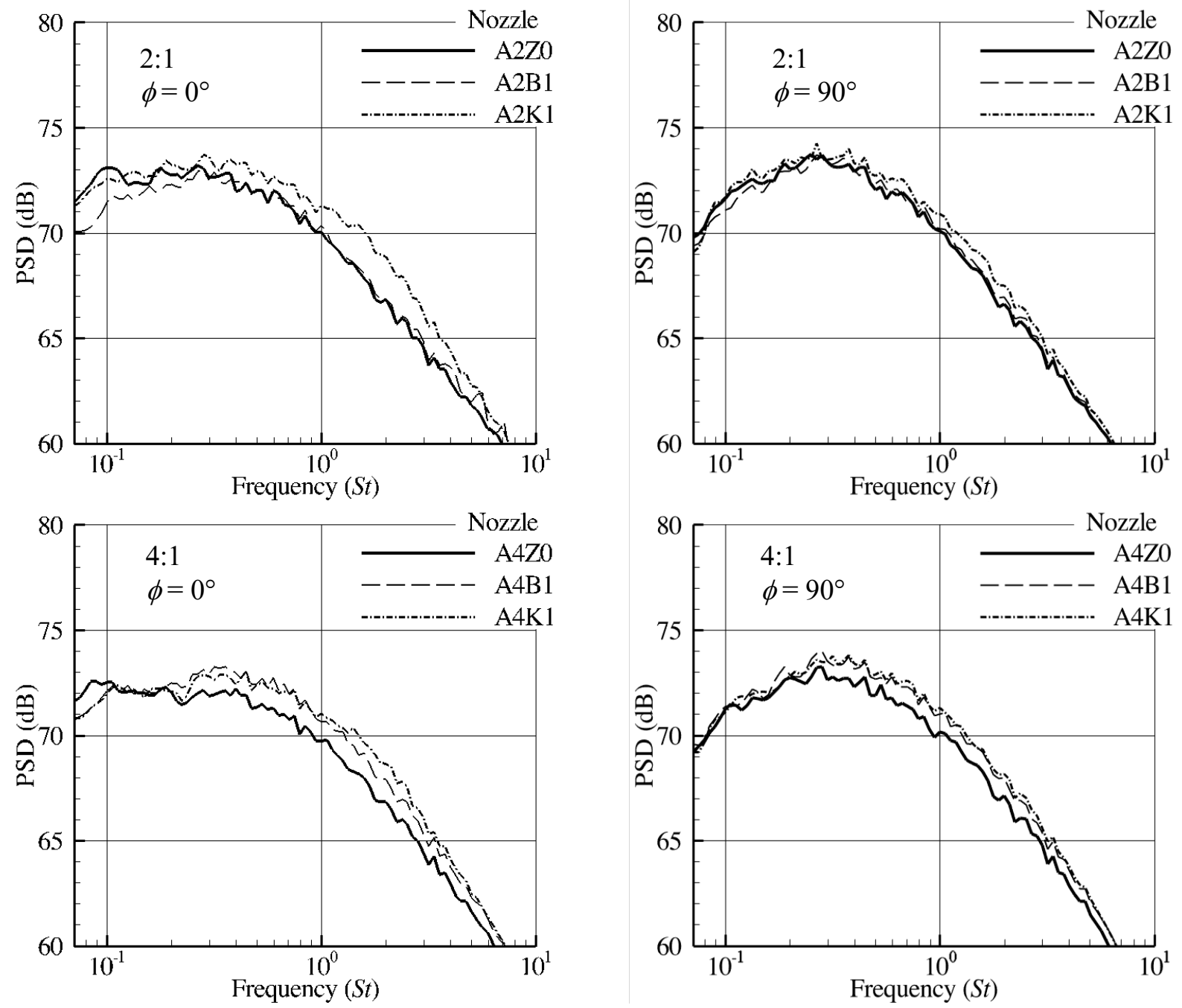

Figure 7.-Power spectral density at polar angle $90^{\circ}$ and azimuthal angles $0^{\circ}$ (left) and $90^{\circ}$ (right) for $2: 1$

(top) and 4:1 (bottom) nozzles with different bevel styles but same lengths. Nozzles $A \cdot Z 0$ have no

extension, $\mathrm{A} \cdot \mathrm{B} 1$ have triangular sidewall while $\mathrm{A} \cdot \mathrm{K} 1$ does not. All jets were run unheated at $\mathrm{Ma}=0.5$.

\section{Presentation of Noise of Nozzle With Plate Surface}

Further extending the aft deck length would be expected to further increase the noise, a trend which is borne out in Figure 8 which compares the power spectral density of noise for the rectangular nozzles with surfaces extending up to 12 in. or $x_{T E} / D=5.6$. The plots in the figure are laid out similarly to Figure 6 , except that the second column of plots is for data acquired at azimuthal angle $\phi=180^{\circ}$, with the observer on the side of the plate opposite the jet. This has sometimes been referred to as the shielded side as opposed to the reflected side of the jet. Beyond the expected increase in noise with increases aft deck length, the plots convey how the extra noise is observed on both sides of the aft deck. At the lowest frequencies the sound reaches roughly the same levels on both sides of the plate, with the reflected side $\left(\phi=0^{\circ}\right)$ having a bit broader spectral peak. At the high frequencies there is a notable difference between the noise on the two sides of the jet, with the aft deck reflecting noise to $\phi=0^{\circ}$ and shielding noise to $\phi=180^{\circ}$ relative to the isolated jet $\left(x_{T E} / D_{e}=0\right)$. The shielding is increased with the length of the aft deck, but the reflection is not. Also noteworthy is the fact that, at the largest deck lengths, the extra noise is not dependent upon aspect ratio. 

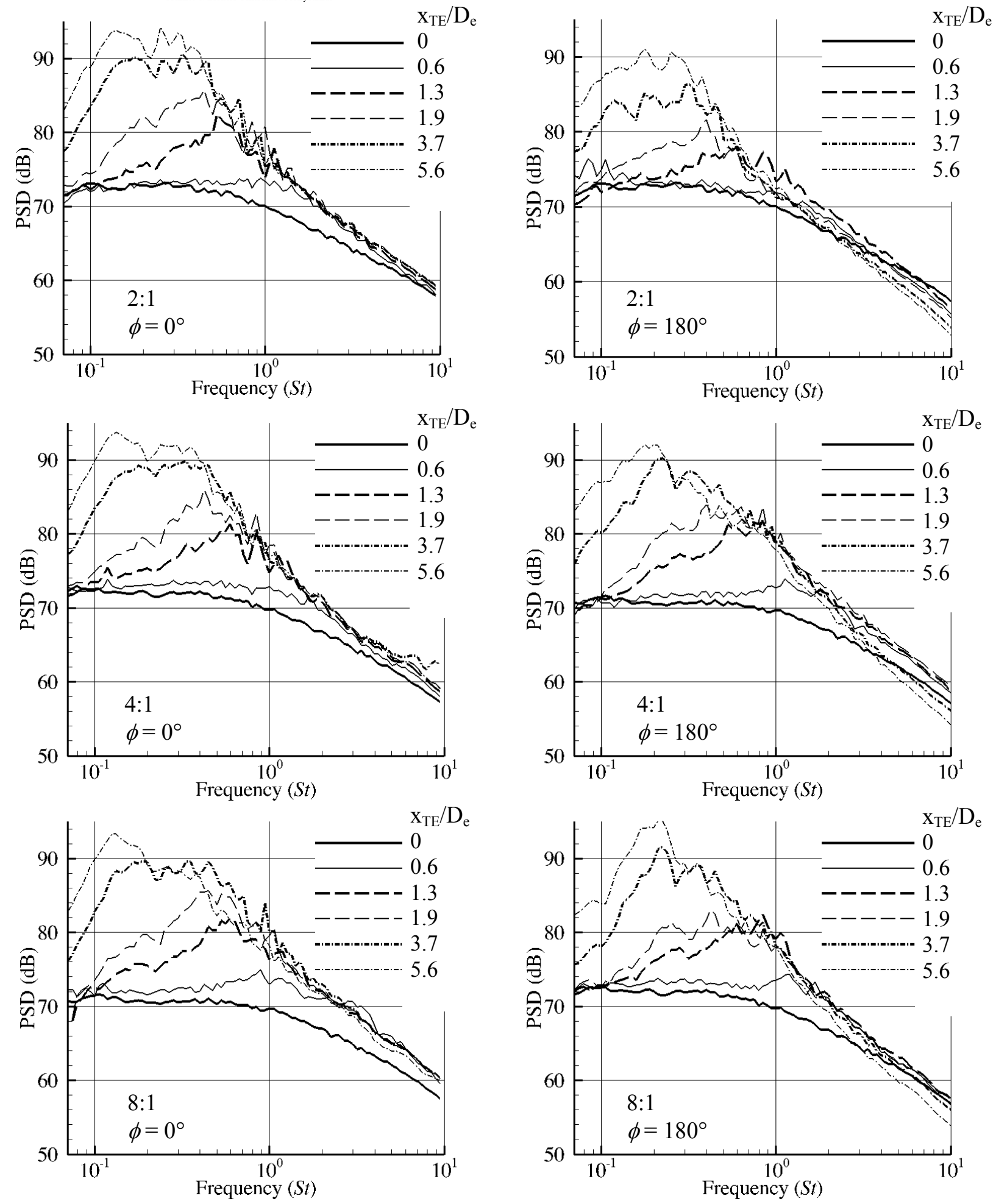

Figure 8.-Power spectral density at polar angle $90^{\circ}$ and azimuthal angles $0^{\circ}$ (left) and $180^{\circ}$ (right) for $2: 1$ (top), 4:1 (middle), and 8:1 (bottom) nozzles with aft deck lengths given in the legend. All aft decks are coplanar with the nozzle lip. All jets run unheated at $\mathrm{Ma}=0.5$. 


\section{Comparison of Noise From Beveled Nozzle and Nozzle With Surface}

Figure 9 directly compares the noise of the two embodiments of an aft deck, the integral, beveled nozzle and basic nozzle with attached plate. In this figure the plots are organized into two columns, the shortest deck $\left(L / D_{e}=0.63\right)$ on the left and the longer deck $\left(L / D_{e}=1.25\right)$ on the right. In each plot the noise spectra of the rectangular nozzle without aft deck and of the rectangular nozzle with the two methods of implementing the deck are put on the same plot. Recall that the difference between the bevel and plate configurations is mostly span of the aft deck and the sidewalls, as shown in Figure 5.

The two aft deck simulations produced similar overall results in a few ways: both aft decks produced greater sound than a jet without the deck, and the added noise increased with increasing aft deck length. However, there were significant differences: the separate plate configuration produced more noise than the beveled version when the nozzle had a low aspect ratio; the spectra of the separate plate versions were not as smooth - the separate plate configurations displayed tonal character. What is not readily apparent, but can be confirmed by overlaying the plots in each column, is that the noise spectra of the separate plate configurations on the different aspect ratios were nearly the same for each plate length. This is in contrast with the noise spectra of the beveled nozzles with the same length aft deck, which increase in amplitude with increasing aspect ratio.

Noise spectra of the two configurations are replotted in Figure 10 to directly compare beveled nozzles of all aspect ratios at the two different bevel lengths, with the added benefit of presenting the noise from both sides of the bevel in the two columns of plots. The plots in this figure confirm that there was a significant effect of aspect ratio on the noise of the beveled nozzle configurations: the noise increases with increasing aspect ratio. Comparing the two columns of plots it is also clear that the noise at this jet speed was nearly the same on both side of the beveled nozzle, e.g., azimuthal angle $0^{\circ}$ and $180^{\circ}$. This makes sense if the noise at the polar angle of $90^{\circ}$ shown was dominated by a dipole at the trailing edge, aligned normal to the extended lip.

Figure 11 mirrors Figure 10 in layout, but the plots are for the rectangular nozzle with separate plate configurations with $x_{T E} / D_{e}=0.6$ and 1.25. Once again, the noise on both sides of the nozzle were very similar. However, unlike the beveled nozzle implementation of an aft deck, the noise spectra were virtually independent of aspect ratio.

Clearly there is some difference between the two implementations of an aft deck. Whether the difference is due to extending the surface to the sides of the nozzle, to the triangular side walls, plate trailing edge thickness and geometry, or aeroelastic vibration, is unknown. 

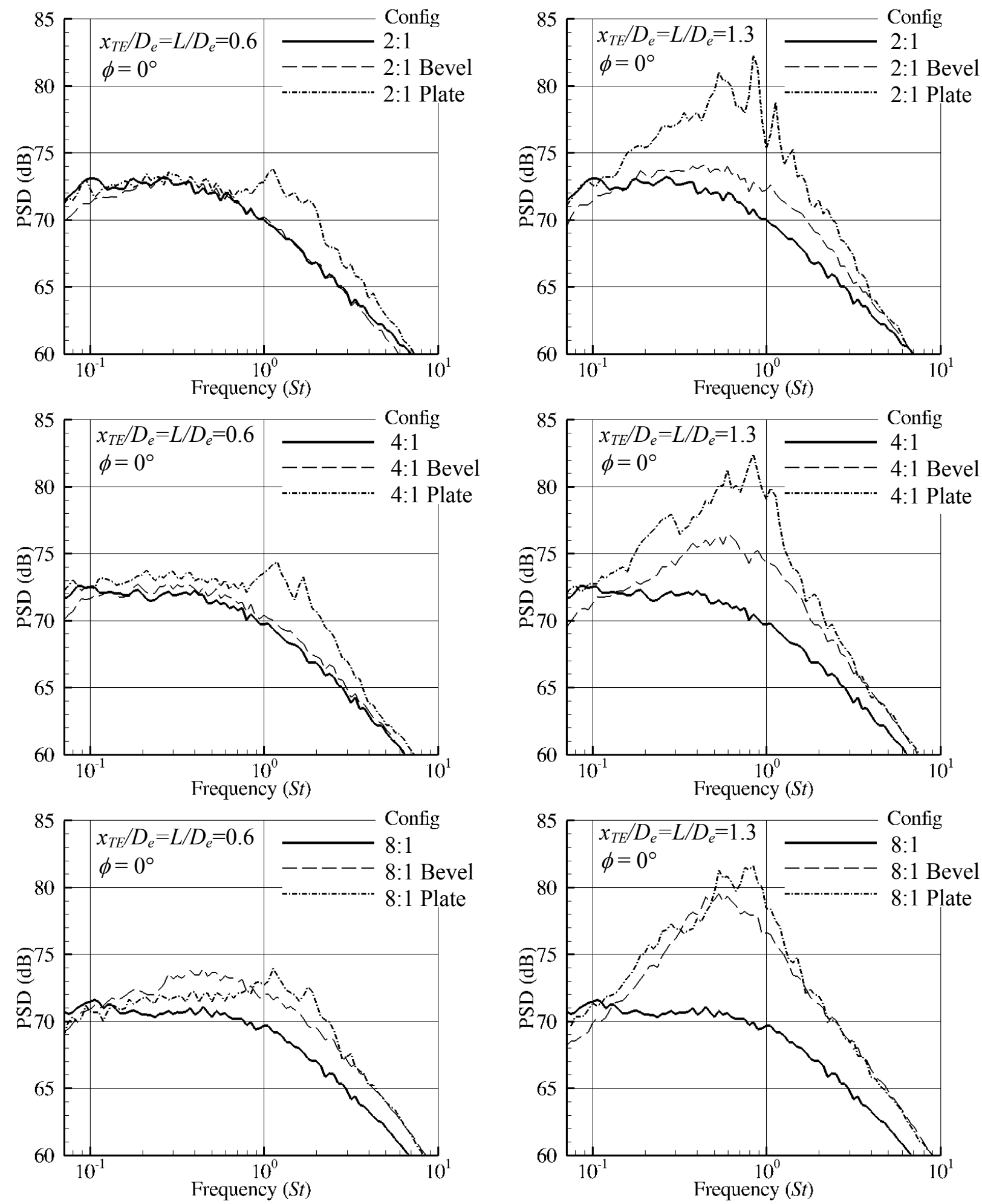

Figure 9.-Power spectral density at polar angle $90^{\circ}$, azimuthal angle $180^{\circ}$ of 2:1 (top), $4: 1$ (middle), and 8:1 (bottom) nozzles with aft decks simulated by beveled nozzle or by separate plate. For each aspect ratio the aft deck length is 0.63 (left) or 1.25 (right). The case of no aft deck is included on all plots for reference. All jets run unheated at $\mathrm{Ma}=0.5$. 

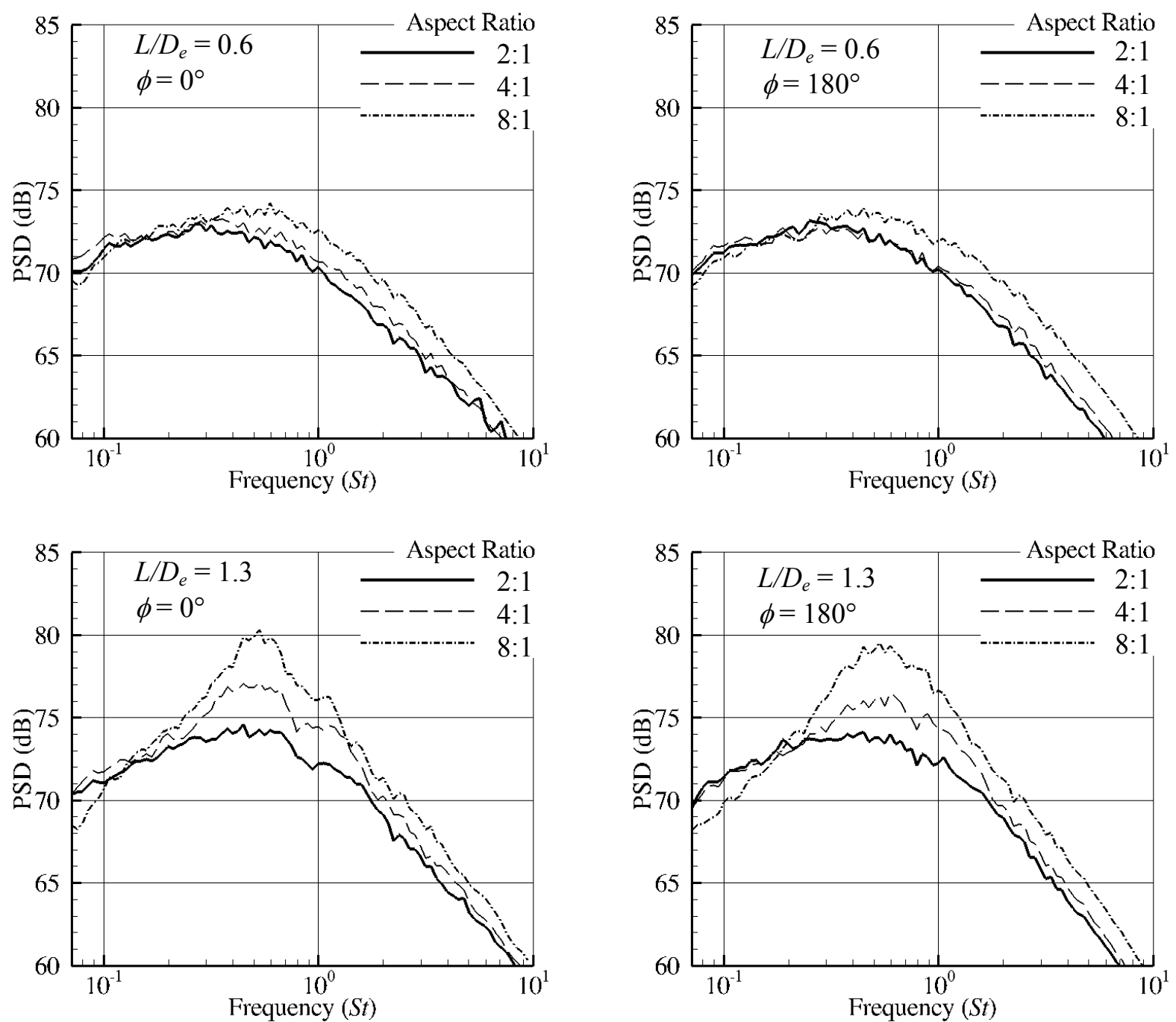

Figure 10.-Power spectral density of sound from beveled rectangular nozzles at polar angle $90^{\circ}$, azimuthal angle $0^{\circ}$ (left) and $180^{\circ}$ (right). Nozzles with bevel length $L / D=0.63$ (top) and $L / D=1.25$ (bottom). All jets run unheated at $\mathrm{Ma}=0.5$. 

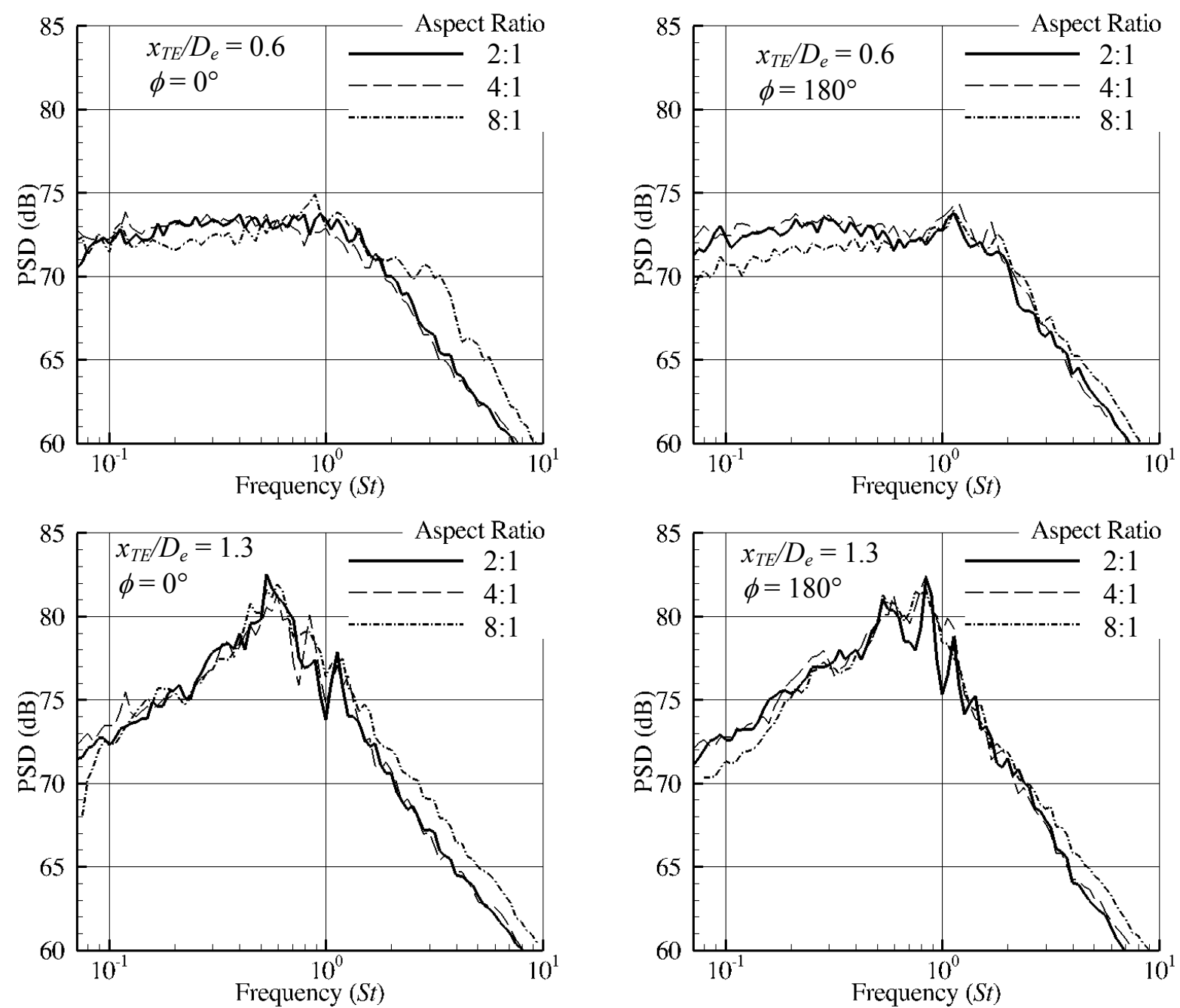

Figure 11.-Power spectral density of sound from rectangular nozzles with separate plate at polar angle $90^{\circ}$, azimuthal angle $0^{\circ}$ (left) and $180^{\circ}$ (right). Nozzles with plate lengths $x_{T E} / D_{e}=0.63$ (top) and with $x_{T E} / D_{e}=1.25$ (bottom). All jets run unheated at $\mathrm{Ma}=0.5$.

\section{Discussion}

The spectra for the separate plate configurations in Figure 11 had an almost tonal spectral character, with the details of the spectra changing slightly from one side of the plate to the other. It must be noted that the measurements on the two sides of the plate were not acquired at the same time: the plate was repositioned while the nozzle and microphones remained fixed. The plate was not remounted, however, for changes in jet speed. It is possible that the spectral details, which differ from one side to the other (one column of plots to another in Figure 11), may be an artifact of the lack of repeatability in mounting the plate on the jet rig. We were alerted to this possibility by supporting work being done in a related test that explored the problem of plate resonance and aeroelastic response (Ref. 13). However, very recent data, using an entirely different jet rig and surface mounting system reproduced the spectral details to a fine degree, reducing the likelihood of this explanation. Also, it was found that the spectral details changed when the same surface plate was used with nozzles of different aspect ratios and different jet speeds, again reducing the chance that the noise is aeroelastic in origin. 


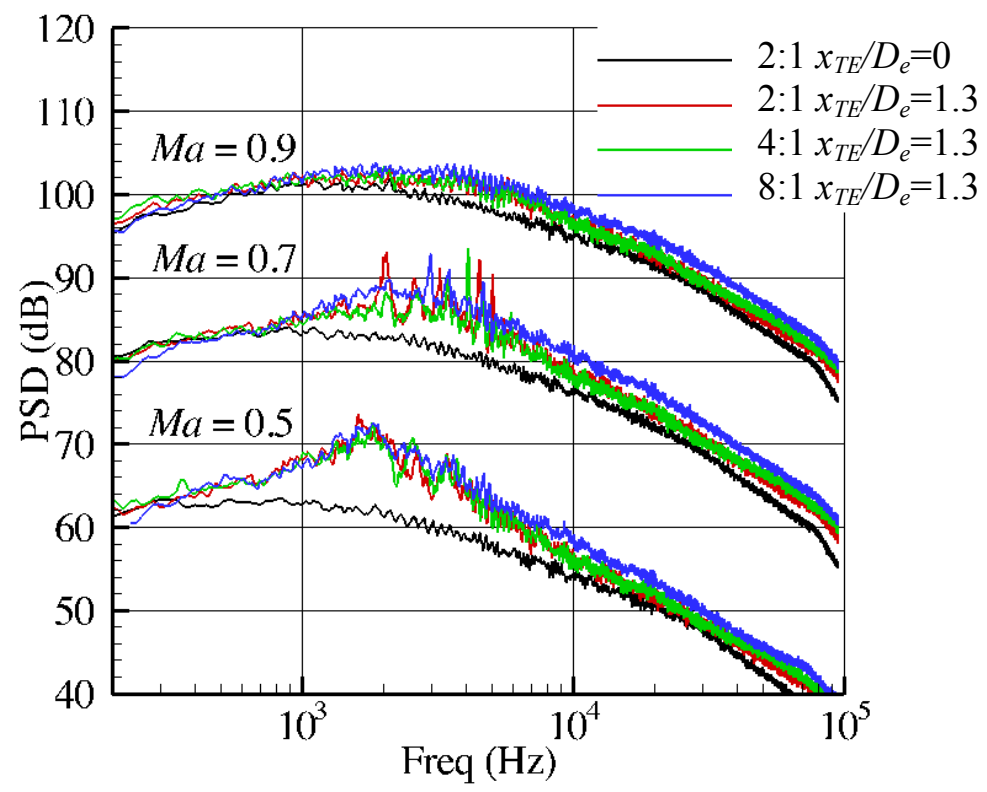

Figure 12.-Power spectral density of sound from rectangular nozzles with the same surface plate of length 2.7 in. at polar angle $90^{\circ}$, azimuthal angle $0^{\circ}$ for three different aspect ratios and three jet flow speeds. Each spectra offset by an additional $10 \mathrm{~dB}$ for clarity. Note spectra are in dimensional form to detect fixed frequency caused by common plate resonance, if such had existed.

Figure 12 was prepared to make this point, and to show how the effect of the surface varied with jet speed relative to a jet with no surface. Compared with the smooth spectrum of jet mixing noise, represented in the figure by the spectra from the basic 2:1 rectangular nozzle, the spectral character with the 2.7 in. plate was somewhat tonal, and these tonal features varied with aspect ratio and jet speed. At $\mathrm{Ma}=0.5$, the spectra of the different aspect ratio jets becomes spiky between 2 to $5 \mathrm{kHz}$. Although the peak was at approximately the same frequency for all aspect ratios, significant differences occurred at the higher frequencies. At $\mathrm{Ma}=0.7$ the spectra became very rich in roughly the same frequency range with clear tones $5 \mathrm{~dB}$ above the broadband. Again, these tones were not the same for the different aspect ratios nor did they match the peaks in the $\mathrm{Ma}=0.5$ spectra. Finally, these effects were gone at $\mathrm{Ma}=0.9$, the spectra being again smooth like jet mixing noise, but elevated from the spectra of the basic rectangular nozzle. If these tonal characteristics came from induced plate vibrations they would have remained fixed for different aspect ratios and jet speeds. And even if the plate resonances had been altered by the remounting of the plate between changes of the nozzles, the resonances would not have changed between jet speeds as the plate was not remounted for changes in jet speed. A companion effort (Ref. 13) using the same nozzles in a different facility explored plate resonance and other mechanisms, and the character of that noise source is quite different than what is reported here. For these reasons it appears that the tonal character of the edge noise has origins in fluid mechanics rather than in plate vibrations. Or it may be better understood as an acoustic aspect of the trailing edge noise as studied in the scattering of turbulent pressure over trailing edges of airfoils (Ref. 14).

The other strong point made by the figure is that the impact of the surface is strongest at lower jet speeds. Accepting that the surface effect is a trailing edge dipole this is expected, since the dipole will vary as velocity to the sixth power compared with eighth power scaling of the jet mixing noise. The tonal aspects of the edge noise complicate this simple explanation, but this scaling generally holds for the data acquired. However, this explanation shows why the previously created model (Ref. 9), which assumed that the geometric effects of the surface were independent of jet flow condition, is faulty. Instead of treating the geometric impact as a simple multiplier on the jet mixing noise, the impact must be taken as having a different flow scaling, a task being undertaken presently. 
Of all the differences between the two embodiments of an aft deck, three will be discussed in the remaining paragraphs: trailing edge geometry, sidewalls, and surface span.

The differences in the trailing edge thickness of the aft deck would seem likely to change the source strength of a trailing edge dipole (Ref. 15). However, preliminary attempts to modify the trailing edge geometry have shown this to not be a factor. Recent data to be published in a later report used the same $1 / 2$ in. thick surface plate but varied the chisel angle of the trailing edge and found that the geometry did not strongly influence the noise of the surface plate.

Another difference in the embodiments was the presence of a triangular sidewall in the bevel nozzle configuration. Given that the theory for trailing edge noise shows strong dependence of the noise upon the character of the turbulence passing over the edge it would seem significant that the shear layer normal to the surface be very different with and without the sidewall. Recall, however, that the difference in the bevel nozzles with the sidewall cut away was not nearly as great as the difference between the bevel and the simple surface. (Compare Figure 7 and Figure 9.) Thus it seems that the presence of the sidewall is not itself a significant feature for the noise.

The final difference in the embodiments was the spanwise extent of the aft deck, non-existent in the bevel nozzle case, and 12 equivalent diameters across in the case of the surface plate. The fact that the aft deck noise in the surface plate configuration was independent of the aspect ratio, whereas the bevel nozzle was strongly dependent upon the aspect ratio, is a strong indication that the span size is a significant effect. In both cases the upper, off-surface, shear layer from the jet nozzle was the same distance from the trailing edge, making this part of the source strength independent of embodiment. In the bevel nozzle version of an aft deck, however, the span of the surface is given by the width of the rectangular nozzle. As the span (width) increased with aspect ratio the efficiency of the trailing edge noise may be increasing. Work on the impact of the surface span is underway that may shed light on the acoustic significance of this aspect of the aft deck design. The possibility of constructive-destructive interference from noise propagating around the fore and aft edges of the plate, as considered in (Ref. 16) was eliminated by carefully covering that the forward edge of the plate, effectively extending it to infinity. Clearly more effort is needed to carefully document the effect of span on the acoustic impact of the aft deck as end effects will vary significantly depending upon aircraft architecture and propulsion installation.

\section{Summary}

Two embodiments of a rectangular nozzle on an aft deck were tested and the spectral directivities of the noise compared. Making the aft deck an integral part of the nozzle was possible for relatively short deck lengths, but a separate plate version was more readily fabricated, accounted for an expanse of deck to the sides of the nozzle, and allows the nozzle to stand off from the deck in future tests.

In both embodiments, and for all aspect ratios, there was a noise penalty for having an extended deck. The noise increased with deck length, and in the case of the beveled nozzle it increased with increasing aspect ratio. There were distinct differences in the noise produced by the aft deck between the two embodiments. When a semi-infinite plate simulated the aft deck the noise spectra showed tonal characteristics that were not present when the aft deck was simulated by a beveled nozzle. The source of the spectral character is under investigation, but seems to be most strongly influenced by the cross-stream span of the surface.

It is noted that the increased noise from the extended aft deck appeared as a dipole at the aft deck trailing edge, an acoustic source type with different dependence on velocity than jet mixing noise. Therefore, it is critical that empirical models of the surface effect depend upon flow condition beyond the basic jet mixing noise scaling. 


\section{References}

1. Coles, W.D., "Jet-Engine Exhaust Noise from Slot Nozzles," NASA Technical Note D-60, Lewis Research Center, September 1959.

2. Dorsch, R.G., E.A. Kresja, and W.A. Olsen, "Blown Flap Noise Research," AIAA Paper No. 71745, June 1971.

3. Schrecker, G.O.H., "Turbulence and Aerodynamic Noise Characteristics of Jet Flap Type Exhaust Flows," Ph.D. Thesis, The University of Tennessee, 1972.

4. Gruschka, H.D.; Schrecker, G.O., "Aeroacoustic characteristics of jet flap type exhausts,” AIAA Paper 72-130, 1972.

5. Olsen, W.A. and Boldman, D., "Preliminary Study of the Effect of the Turbulent Flow Field Around Complex Surfaces On Their Acoustic Characteristics," AIAA paper 1978-1123, presented at 11th Fluid and Plasma Dynamics Conference, Seattle, Washington, July 10-12, 1978.

6. Amiet, R.K., "Acoustic Radiation from an Airfoil in a Turbulent Stream," Journal of Sound and Vibration, 41 (4), pp. 407-420, 1975.

7. Brown, C.A., "Developing an Empirical Model for Jet-Surface Interaction Noise," AIAA Paper 2014-0878, presented at 52nd AIAA Aerospace Sciences Meeting, 13-17 January 2014.

8. Munro, S.E. and Ahuja, K.K., "Development of a Prediction Scheme for High Aspect-Ratio Jet Noise," AIAA paper 2003-3255, presented at 9th AIAA/CEAS Aeroacoustics Conference, Hilton Head, South Carolina, 12-14 May 2003.

9. Bridges, J., "Acoustic Measurements of Rectangular Nozzles with Bevel," AIAA Paper 2012-2252, presented at $19^{\text {th }}$ AIAA/CEAS Aeroacoustics Conference, Colorado Springs, Colorado, June 2012.

10. Brown, C.A., "Jet-Surface Interaction Test: Far-Field Noise Results," J. Eng. Gas Turbines Power, 135(7), June 2013.

11. Bridges, J. and Brown, C.A., "Validation of the Small Hot Jet Acoustic Rig for Jet Noise Research," AIAA Paper 2005-2846, presented at $11^{\text {th }}$ AIAA/CEAS Aeroacoustics Conference, Monterrey, California, June 2005.

12. Frate, F.C. and Bridges, J., "Extensible Rectangular Nozzle Model System," AIAA Paper 20110975, presented at 49 ${ }^{\text {th }}$ AIAA Aerospace Sciences Meeting, January 2011.

13. Zaman, K.B.M.Q., Fagan, A.F., Clem, M.M., and Brown, C.A., "Resonant Interaction of a Rectangular Jet with a Flat-plate," AIAA Paper 2014-xxxx, presented at 52nd AIAA Aerospace Sciences Meeting, 13-17 January 2014.

14. Roger, M., Moreau, S., "Back-scattering correction and further extensions of Amiet's trailing-edge noise model. Part 1: theory," Journal of Sound and Vibration, 286 (3), pp. 477-506, Sept. 2005.

15. Kunze, C., Lynch, D.A., Mueller, T.J., Blake, W.K., "Effect Of Trailing Edge Geometry On Vortex Shedding And Acoustic Radiation," AIAA paper 2002-2435, presented at 8th AIAA/CEAS Aeroacoustics Conference \& Exhibit, Breckenridge, Colorado, 17-19 June 2002.

16. Tam, C.K.W. and Yu, J.C., "Trailing Edge Noise," AIAA paper 75-489, presented at $2^{\text {nd }}$ AIAA Aeroacoustics Conference, Hampton, VA, March 24-26, 1975. 


\begin{tabular}{|c|c|c|}
\hline \multicolumn{2}{|c|}{ REPORT DOCUMENTATION PAGE } & $\begin{array}{l}\text { Form Approved } \\
\text { OMB No. 0704-0188 }\end{array}$ \\
\hline \multicolumn{3}{|c|}{$\begin{array}{l}\text { The public reporting burden for this collection of information is estimated to average } 1 \text { hour per response, including the time for reviewing instructions, searching existing data sources, gathering and } \\
\text { maintiaining the data needed, and completing and reviewing the collection of information. Send comments regarding this burden estimate or any other aspect of this collection of information, including } \\
\text { suggestions for reducing this burden, to Departm ent of Defense, Washington Headquarters Services, Directorate for Information Operations and Reports (0704-0188), } 1215 \text { Jefferson Davis Highway, Suite } \\
1204, \text { Arlington, VA } 22202-4302 \text {. Respondents should be aware that notwithstanding any other provision of law, no person shall be subject to any penalty for failing to comply with a collection of information if it } \\
\text { does not display a currently valid OMB control number. } \\
\text { PLEASE DO NOT RETURN YOUR FORM TO THE ABOVE ADDRESS. }\end{array}$} \\
\hline $\begin{array}{l}\text { 1. REPORT DATE (DD-MM-YYYY) } \\
01-04-2014\end{array}$ & $\begin{array}{l}\text { 2. REPORT TYPE } \\
\text { Technical Memorandum }\end{array}$ & 3. DATES COVERED (From - To) \\
\hline \multirow{2}{*}{\multicolumn{2}{|c|}{$\begin{array}{l}\text { 4. TITLE AND SUBTITLE } \\
\text { Noise From Aft Deck Exhaust Nozzles-Differences in Experimental Embodiments }\end{array}$}} & 5b. GRANT NUMBER \\
\hline & & 5c. PROGRAM ELEMENT NUMBER \\
\hline \multirow{2}{*}{\multicolumn{2}{|c|}{$\begin{array}{l}\text { 6. AUTHOR(S) } \\
\text { Bridges, James, E. }\end{array}$}} & 5d. PROJECT NUMBER \\
\hline & & $\begin{array}{l}\text { 5f. WORK UNIT NUMBER } \\
\text { WBS 475122.02.03.05.02 }\end{array}$ \\
\hline \multicolumn{2}{|c|}{$\begin{array}{l}\text { 7. PERFORMING ORGANIZATION NAME(S) AND ADDRESS(ES) } \\
\text { National Aeronautics and Space Administration } \\
\text { John H. Glenn Research Center at Lewis Field } \\
\text { Cleveland, Ohio 44135-3191 }\end{array}$} & $\begin{array}{l}\text { 8. PERFORMING ORGANIZATION } \\
\text { REPORT NUMBER } \\
\text { E-18866 }\end{array}$ \\
\hline \multicolumn{2}{|c|}{$\begin{array}{l}\text { 9. SPONSORING/MONITORING AGENCY NAME(S) AND ADDRESS(ES) } \\
\text { National Aeronautics and Space Administration } \\
\text { Washington, DC 20546-0001 }\end{array}$} & $\begin{array}{l}\text { 10. SPONSORING/MONITOR'S } \\
\text { ACRONYM(S) } \\
\text { NASA }\end{array}$ \\
\hline
\end{tabular}

\section{SUPPLEMENTARY NOTES}

\section{ABSTRACT}

Two embodiments of a rectangular nozzle on an aft deck are compared. In one embodiment the lower lip of the nozzle was extended with the sidewalls becoming triangles. In a second embodiment a rectangular nozzle was fitted with a surface that fit flush to the lower lip and extended outward from the sides of the nozzle, approximating a semi-infinite plane. For the purpose of scale-model testing, making the aft deck an integral part of the nozzle is possible for relatively short deck lengths, but a separate plate model is more flexible, accounts for the expanse of deck to the sides of the nozzle, and allows the nozzle to stand off from the deck. Both embodiments were tested and acoustic far-field results were compared. In both embodiments the extended deck introduces a new noise source, but the amplitude of the new source was dependent upon the span (cross-stream dimension) of the aft deck. The noise increased with deck length (streamwise dimension), and in the case of the beveled nozzle it increased with increasing aspect ratio. In previous studies of slot jets in wings it was noted that the increased noise from the extended aft deck appears as a dipole at the aft deck trailing edge, an acoustic source type with different dependence on velocity than jet mixing noise. The extraneous noise produced by the aft deck in the present studies also shows this behavior both in directivity and in velocity scaling.

\section{SUBJECT TERMS}

Aeroacoustics; Jet noise; Aft deck

\begin{tabular}{|c|c|c|c|c|c|}
\hline \multicolumn{3}{|c|}{ 16. SECURITY CLASSIFICATION OF: } & \multirow{3}{*}{$\begin{array}{l}\text { 17. LIMITATION OF } \\
\text { ABSTRACT } \\
\text { UU }\end{array}$} & \multirow{3}{*}{$\begin{array}{l}\text { 18. NUMBER } \\
\text { OF } \\
\text { PAGES } \\
24\end{array}$} & \multirow{2}{*}{$\begin{array}{l}\text { 19a. NAME OF RESPONSIBLE PERSON } \\
\text { STI Help Desk (email:help@sti.nasa.gov) }\end{array}$} \\
\hline a. REPORT & b. ABSTRACT & c. THIS PAGE & & & \\
\hline & & & & & $\begin{array}{l}\text { 19b. TELEPHONE NUMBER (include area code) } \\
443-757-5802\end{array}$ \\
\hline
\end{tabular}



